antirheumatic drugs, shared care, and the proper selection of patients for surgery, as well as examination and the optimal use of remedial therapists.

Ideally rheumatology would be included in vocational training programmes. Three months would be long enough for trainees to learn the examination of the locomotor system and differential diagnosis, the management of rheumatic conditions, and the value of remedial services and intraarticular injection techniques. Emphasis should be given to services in the community-trainees should, for instance, visit an aids centre. In practice, however, in the Greater London regions there are only nine senior house officer posts in rheumatology or orthopaedics out of 272 posts offered in the specialties. $^{10}$

At the University of Dundee Dunn and Wilkinson ${ }^{11}$ have devised a distance learning programme in rheumatology which is convenient, relevant, individual, and systematic. It allows the individual to learn as much or as little as he wishes with possibilities for self assessment and feedback. They argued that since less than one fifth of general practitioners attend existing courses in continuing education an alternative was required. Nearly 4000 doctors have been enrolled in the course, which seems to fill a real need. Pharmaceutical companies are helping in the pioneering of this and other schemes using microcomputers. In a country committed to a mixed economy this is a welcome contribution from the drug industry. The consultant's letter and discharge summary will remain a major teaching vehicle, and audit of these would be beneficial, as would the audit of general practitioner referral letters. It was encouraging to learn from Professor Michael Drury at the Arthritis and Rheumatism Council symposium that general practitioners who suffer from lack of peer review are moving toward an audit of their handling of certain patients (for example, those with backache), at least in group practices. The Royal College of General Practitioners is willing to look at new educational initiatives in rheumatological training for general practice.

Future improvements in education should include apprenticeship schemes, small group teaching, and discussion between consultants and general practitioners over shared topics which should contribute to the development of skills in problem solving, injection techniques, application of remedial treatments, and use of rheumatological consultants. Consultants are still likely to be invited to give traditional formal lectures to general practitioners at postgraduate centres, or more popularly at hotel meetings sponsored by a pharmaceutical company. They would do well to consider whether to suggest to the organisers a change of presentation to one of the more effective teaching formats with participation by the audience.

VERNA WRIGHT

Professor of Rheumatology,

University of Leeds.

Leeds LS2 9PJ

Wood PH, Badley EM. Setting disablement in perspective. Int Rehabil Med $1978 ; 1: 32-7$.

Wright V. The epidemiology of disability. 7 R Coll Physicians Lond 1982; 16:178-83.

"Wood P. The challenge of arthritis. London: Arthritis and Rheumatism Council, 1977.

- Billings RA, Mole KF. Rheumatology in general practice-a survey in world rheumatism year 1977. 7 R Coll Gen Pract 1977;27:721-5.

${ }^{5}$ Golding DN. Postgraduate education in rheumatology: who should teach what and to whom? f $R$ Soc Med 1982;75:985-6.

${ }^{6}$ Anonymous. Undergraduate education in rheumatology. Br Med $\mathcal{F} 1979$; ii $: 885-6$.
Wright V, Hopkins R, Burton KE. What shall we teach undergraduates ? Br Med F 1979;i:805-7.

${ }^{8}$ Griffin GA. Continuing education in rheumatology. $\mathcal{f} R$ Soc Med (in press).

${ }^{9}$ Griffin GA, Barry SMK. Muscle and joint pain: design and evaluation of courses for general practitioners. $7 R$ Coll Gen Pract 1981;31:661-8.

10 Thames Health Region. Doctors' study guide. London: THR, 1981-2.

${ }^{11}$ Dunn WR, Wilkinson M. Foint studies in rheumatology: a complete course for general practitioners. Sandwich: Committee for Medical Education, University of Dundee, and Pfizer Limited, 1982.

\section{Drugs or oxygen for hypoxic cor pulmonale?}

Cor pulmonale-chronic respiratory failure associated with recurrent exacerbations of oedema in patients with chronic obstructive airways disease-has a poor prognosis. ${ }^{12}$ The results of two recent studies ${ }^{3}{ }^{4}$ suggest that long term domiciliary oxygen improves the prognosis by increasing the concentration of arterial oxygen for substantial parts of the day. Oxygen exerts its effect by improving tissue oxygenation and reducing the rise of pulmonary artery pressure. ${ }^{3}$ Studies in animals ${ }^{5}$ and observations in man have shown that chronic hypoxaemia causes an increase in the thickness of the right ventricular muscle and of the walls of small pulmonary vessels, an increase in pulmonary vascular resistance, and pulmonary hypertension.

Cor pulmonale has long been considered to be a form of congestive heart failure associated with progressive pulmonary hypertension. Nevertheless, studies of right heart function have given conflicting results and some have failed to show right heart failure even in the presence of gross peripheral oedema. Furthermore, cardiac output tends to remain normal or even slightly raised at rest and responds normally to what little exercise the respiratory system will permit until shortly before death. ${ }^{6}$ The pulmonary artery pressure does, however, correlate with outcome, the rise in pressure being associated with diminishing survival, ${ }^{7}$ but this association is not necessarily causal. The effects of chronic hypoxaemia and hypercapnia on the renin angiotensin system and on antidiuretic hormone are being studied in an attempt to discover alternative explanations for the oedema. In acute episodes of respiratory failure renal blood flow falls despite a normal cardiac output and plasma renin activity and aldosterone concentrations rise, ${ }^{89}$ findings which support an alternative effect of the alteration in blood gas concentration.

There are therefore two approaches to treatment: oxygen to relieve hypoxaemia and to reverse pulmonary arteriolar vasoconstriction, and pulmonary hypotensive agents which act directly to reduce pulmonary hypertension and right ventricular afterload. Domiciliary oxygen is increasingly accessible with the introduction of the oxygen concentrator, a machine which converts environmental air into a stream of $90 \%$ oxygen. It is simple to use but the patient must take oxygen for at least 15 hours a day and the equipment requires careful maintenance. ${ }^{10}$ Patients with severe respiratory failure $\left(\mathrm{PaO}_{2}<6.0 \mathrm{kPa} ;<45 \mathrm{~mm} \mathrm{Hg}\right)$ are least likely to benefit from this form of treatment.

Almitrine is a new drug from France which offers an exciting new therapeutic approach, although it has not yet been fully evaluated. It improves $\mathrm{PaO}_{2}$ and $\mathrm{PaCO}_{2}{ }^{11}$ and may reduce the need for domiciliary oxygen in the early stages of disease and 
later be a useful adjunct to the oxygen concentrator. Its effects on the pulmonary circulation appear to be small.

Several pulmonary hypotensive agents have been studied but it is important to distinguish between the results of studies on patients with cor pulmonale secondary to chronic obstructive airways disease from those in patients with primary or embolic pulmonary hypertension, where the pulmonary arterial pressures are much higher. Prazosin, nitroprusside, phentolamine, nifedipine, verapamil, isosorbide, chlorpheniramine, and captopril have all been used to reduce pulmonary hypertension and pulmonary vascular resistance, and usually do so by $15-25^{\circ} \cdot{ }^{12-14}$ Their pharmacological actions differ, but the short duration of the response observed in many single dose studies shows that multiple daily doses over long periods will be necessary for a sustained effect on the pulmonary circulation. Cardiac output and cardiac index have improved in some studies but have been unchanged in most. The crucial question is whether the effects of drug treatment on pulmonary vascular resistance and cardiac output will prevent progressive clinical deterioration and improve mortality. This will be established only when the results of long term placebo controlled studies are available.

Catecholamines may act as pulmonary mediators of the hypoxic response, ${ }^{15}$ and it is of interest that methyldopa can prevent the development of pulmonary hypertension and the changes in small pulmonary vessels and the right ventricle in hypoxic animals. ${ }^{16}$ This effect is likely to be at a more fundamental level than reduction of pulmonary hypertension, for reversal of the vascular changes did not occur once they were well established. Whether methyldopa can exert any influence on the clinical course of cor pulmonale is not yet known.

Bronchodilators play an important part in the treatment of chronic obstructive airways disease and they may also affect the pulmonary circulation. Aminophylline and related theophylline compounds dilate airways and increase cardiac output, but they may also cause arrhythmias and a deterioration of arterial blood gases in the hypoxic patient with bronchitis. Isoprenaline, an important bronchodilator, has pronounced inotropic and chronotropic actions, and at one stage it was accused of causing several deaths in asthmatics by precipitating ventricular fibrillation when used in high dosage. ${ }^{17} 18 \mathrm{~A}$ search for more selective bronchodilators spawned the beta ${ }_{2}$ adrenergic agonists, of which the best known are salbutamol, terbutaline, and fenoterol. Salbutamol has a weak inotropic effect on heart muscle but may cause a definite improvement in cardiac output and a fall in systemic vascular resistance. ${ }^{19}$ Pulmonary vasodilatation occurs but the effect seems to be smaller than that on peripheral systemic resistance. Terbutaline has a similarly weak inotropic action, and it increases cardiac output and reduces both peripheral and pulmonary vascular resistance. The effect on pulmonary vascular resistance appears to be more prominent than with salbutamol, but no formal comparisons have been made. ${ }^{20}{ }^{21}$ It has even been suggested that these two agents might be used to treat congestive cardiac and left ventricular failure. There appears to be only one study of the cardiovascular effects of fenoterol, which shows similar effects. ${ }^{22}$

A new beta agonist, pirbuterol, has little or no action on the airways but it does have appreciable inotropic action and vasodilator properties acting on both the pulmonary and systemic vessels ( $p p 1169,1178$ ). In short term studies in hypoxic patients with bronchitis it reduced mean pulmonary vascular resistance and improved right ventricular ejection fraction and cardiac output without appreciable deterioration of arterial oxygen tension. The changes were maintained during six weeks of oral administration, the longest period of study. Hypoxaemia will continue to require independent treatment. Whether the cardiac inotropic effect is a real advantage compared with the predominant vasodilator properties of the beta ${ }_{2}$ agonists (which also have useful actions on the airways) can be determined only by long term studies. Studies of the pharmacological effects of new compounds such as pirbuterol are provoking great interest but claims that they represent a major breakthrough in the treatment of hypoxic cor pulmonale are premature.

Peter Howard

Reader in Medicine and Consultant Physician, Hallamshire Hospital,

Sheffield S10 2JF

${ }^{1}$ Renzetti AD Jr, McClement JH, Litt BD. The Veterans Administration co-operation study of pulmonary function. 3. Mortality in relation to respiratory function in chronic obstructive pulmonary disease. $A m \mathcal{F}$ Med 1966;41:115-29.

2 Ude AC, Howard P. Controlled oxygen therapy and pulmonary heart failure. Thorax $1971 ; 26: 572-8$.

${ }^{3}$ Medical Research Council Working Party. Long term domiciliary oxygen therapy in chronic hypoxic cor pulmonale complicating chronic bronchitis and emphysema. Lancet $1981 ; \mathrm{i}: 681-5$.

${ }^{4}$ Nocturnal Oxygen Therapy Trial Group. Continuous or nocturnal oxygen therapy in hypoxemic chronic obstructive airways disease: a clinical trial. Ann Intern Med 1980;93:391-8.

${ }^{5}$ Leach E, Howard P, Barer GR. Resolution of hypoxic changes in the heart and pulmonary arterioles of rats during intermittent correction of hypoxia. Clinical Science and Molecular Medicine 1977;52:153-62.

${ }^{6}$ Finlay M, Middleton HC, Peake MD, Howard P. Cardiac output, pulmonary hypertension, hypoxaemia and survival in patients with chronic obstructive airways disease. Eur $\mathcal{F}$ Respir Dis 1983;64:252-63.

'Wietzenblum E, Hirth C, Ducolone A, Mirhom R, Rasaholinjanahary J, Ehrhart $M$. Prognostic value of pulmonary artery pressure in chronic obstructive pulmonary disease. Thorax $1981 ; \mathbf{3 6}: 752-8$

' Stuart-Harris CH, MacKinnon J, Hammond JDS, Smith WD. Renal circulation in chronic pulmonary disease and pulmonary heart failure. Q7 Med 1956;25:389-405.

${ }^{9}$ Brown JJ, Davies DL, Johnson VW, Lever AF, Robertson JIS. Renin relationships in congestive cardiac failure, treated and untreated. $A m$ Heart f $1970 ; 80: 329-42$.

${ }^{10}$ Evans TW, Waterhouse J, Howard P. Clinical experience with the oxygen concentrator. $B r$ Med 7 1983;287:459-61.

${ }^{11}$ Arnaud F, et al. Almitrine bismesylate in long term treatment of patients with chronic bronchitis. Bull Eur Physiopathol Respir 1982;18, suppl 4 737-82.

${ }^{12}$ Bucca C, Sclavo M, Rolla G, Borello G, Polizzi S. Verapamil versus oxygen in pulmonary hypertension complicating chronic obstructive lung disease. Bull Eur Physiopathol Respir 1982;18, suppl 4:87-93.

${ }^{13}$ Rengo F, Trimarco B, Ricciardelli B, et al. Histamine and hypoxic pulmonary hypertension. Bull Eur Physiopathol Respir 1980;16:109-11.

${ }^{14}$ Cernohorsky D, Hamet A, Kral B. The influence of nifedipine on hypoxic pulmonary hypertension. Bull Eur Physiopathol Respir 1983;19:58.

${ }^{15}$ Barer GR, McCurrie JR. Pulmonary vasomotor responses in the cat; the effects of drugs, hypoxia and hypercapnia. O f Exp Physiol 1969;54 156-72.

${ }^{16}$ Suggett AJ, Herget J. Effects of alpha-methyldopa on the pulmonary vascular changes induced by chronic hypoxia in rats. Clinical Science and Molecular Medicine 1977;53:397-400.

17 Speizer FE, Doll R, Heaf P, Strang LB. Investigation into use of drugs preceding death from asthma. $\mathrm{Br}$ Med $\mathcal{F}$ 1968;i:339-43.

18 Conolly ME, Davies DS, Dollery CT, George CF. Resistance to $\beta$ adrenoreceptor stimulants (a possible explanation for the rise in asthma deaths). Br F Pharmacol 1971;43:389-402.

19 Iodice F, Rufolo L, Piscione F, De Michele G. Hemodynamic and ventilatory effects of intravenous salbutamol in patients affected by COLD. Respiration $1980 ; \mathbf{4 0}: 272-7$.

${ }^{20}$ Stockley RA, Finnegan P, Bishop JM. Effect of intravenous terbutaline on arterial blood gas tensions, ventilation, and pulmonary circulation in patients with chronic bronchitis and cor pulmonale. Thorax 1977;32 601-5.

${ }^{21}$ Jones RM, Stockley RA, Bishop JM. Early effects of intravenous terbutaline on cardiopulmonary function in chronic obstructive bronchitis and pulmonary hypertension. Thorax $1982 ; 37: 746-50$.

22 Assestrup S, Henriksen L, Ryss IH, Lauridsen P. The cardiovascula and respiratory effects of fenoterol in patients after open-heart surgery f Cardiovasc Surg (Torino) 1980;21:409-16. 